\title{
Evaluation of Women's Football National Training Program in Asian 2018 Games
}

\author{
Alex Aldha Yudi* \\ The Faculty of Sport Sciences, Universitas Negeri Padang, Indonesia \\ *Corresponding author. Email: alexaldha@yahoo.com
}

\begin{abstract}
The program to improve football's ability for women must be held as soon as possible. The program is expected to produce soccer players who have good competence in playing football. This periodic research program uses the CIPP model and the context that includes the context, inputs, processes and products as follows: (a) the policies of the football management federation in Indonesia, (b) women's soccer training programs, (c) the profile and background of female players, (d) the level of qualification of the game, training and practice content of Indonesian female players, (e) the completeness of training facilities and infrastructure, (d) the conformity of the football curriculum in Indonesia with the needs of today's modern football, (e) the learning process before the game begins, (f) the effectiveness of the exercise program implementation, (g) the results before the Asian Games begin, (h) the results of the 2018 Asian Games test, (i) the absorption of the training program provided by the trainer, $(j)$ the effectiveness and flexibility on women's football.
\end{abstract}

Keywords: Evaluation Program, Women's National Football Team Training, CIPP Model, 2018 Asian Games

\section{INTRODUCTION}

The evaluation that is often understood so far in the world of football is limited to the final outcome of a championship. This assessment is done to see the final performance, is it already on target or not. Such understanding is not too precise. In the case of an exercise program, it is not only to see the final results being assessed, but there are many factors that make a workout program successful or not. The final results are a small part of the evaluation. Evaluation must also be understood as part of supervision. "Evaluation does not only deal with results measured based on the results of matches to matches, but in evaluating training programs will examine many factors, with evaluation of training programs need to be introduced to all soccer coaches, because evaluation is very important in developing football quality, in this case women's soccer for the future" [1].

Evaluation of training programs is a process of searching, finding and determining information made systematically and fulfills the criteria and objectives that have been set. The existence of women's football lately has increased greatly with the number of women's football clubs that have been conducting training from every week. The Indonesian Football Federation continues to strive to improve the quality of women's football which will be an example and role model for players in the future.

The 2018 Asian Games event that has passed has a big impact on Indonesian sports, especially Women's Football, giving hope that women's passion will continue to grow in this country. This Multi Event became the first agenda after several years of not actively participating in women's football at senior level in both Southeast Asia and Asia. Indonesia obtained a one-time victory and twice defeat in this event.

"The objectives of the program evaluation are to (1) At the context stage, (a) to know the policies of the highest football management federation in Indonesia, (b) know the needs of the community for women's soccer training programs; (2) At the input stage, (a) knowing the profile and background of female players (b) analyzing game level qualifications, training experience and training age for Indonesian female soccer players, (c) knowing the completeness of training facilities and infrastructure, (d) analyzing suitability Indonesian football curriculum with the needs of modern football today; (3) at the process stage, (a) knowing the implementation of the training process before asian games are started, (b) measuring the effectiveness of the exercise program implementation; (4) At the product stage, (a) analyze the results of the trial match before the Asian Games begin, (b) analyze the results of the 2018 Asian Games test, (c) know the absorption of the training program provided by the trainer, (d) recommend guidelines for evaluation of training programs valid, effective and flexible for women's football" [2]. 


\section{RESEARCH METHODOLOGY}

\subsection{Research Methods}

"The research method used in this study is qualitative research using case studies and program evaluation approaches" [3]. According to Wirawan, case studies are one of the research methods that are widely used in program evaluations. Robert K. Yin stated that case studies are stories about something unique, special, interesting. The story can be about individuals, processes, programs, institutions, and even events. The term case shows the topic or unit of analysis chosen for study. The topics or units examined in this study are context, input, process and product in the implementation of the Women's Soccer Team Training Program towards the2018 Asian Games.

\subsection{Research Instruments}

The instrument used in this study is an instrument that is directly used to explore data / information. Researchers used interviews, while as supporting material for researchers in conducting research assisted with documentation data.

\subsection{Data Collection Techniques and Procedures}

The techniques and procedures for collecting data in this study were carried out systematically using interviews, documentation and inventory checklists, qualitative data using multi methods such as interviews, observations and documents.

The process of data collection begins with identifying what data is needed for research activities. In this study data collection was obtained from: 1) Primary data, namely data collected from first hand, or can be said primary data is opinions that are subjective in nature from the respondent and delivered directly. Primary data collection is done through field observations and interviews. 2) Secondary data, namely data obtained from official documents to complete the primary data.

\section{RESEARCH RESULT}

\subsection{Evaluation Context (Context)}

The results of the context evaluation in this study were conducted to evaluate the training program relating to the foundation and the purpose of the exercise program towards the 2018 Asian Games, as well as the feasibility of the organizing agencies namely the Indonesian Football Federation (PSSI).

The objectives of the preparation training towards the 2018 Asian Games are: 1) Increasing the skills, skills and attitudes of a player to be able to carry out their duties professionally based on personality and ethics as a national player; 2) Creating a team capable of acting as a reformer and unifier of Indonesian women's football; 3) Strengthen the attitude and spirit of players who are oriented towards modern football, 4) Create a common vision and dynamics of mindset in implementing the game system that will be used in the actual game.

\subsection{Input Evaluation (Input)}

All 2018 Asian Games soccer players are the best choice players from the 2017 Pertiwi Cup Championship. Based on the data from the initial physical test, the players have good ability in data from Indonesian football players. For the ratio of 30 players to preparation for the 2018 Asian Games, previously there are already around 60 players selected. West Sumatra women's soccer players in Indonesia at the moment are still few, whoever coaches will find it difficult to find the talented players for women's football.

\subsection{Process Evaluation (Process)}

Basically the asian games preparation training program that was carried out was in accordance with the program planning made by the coaching staff. The survey conducted on players said that the implementation time was indeed TC for about 5 months, the length of the training preparation training activities per day and time matched the material presented by the trainers. As for the suitability of training time with the material.

\subsection{Results Evaluation (Product)}

The results of the evaluation of the product focus on 3 criteria, namely: the results of an assessment of individual players, the results of an assessment of the team's achievements at the 2018 Asian Games.

\section{CONCLUSION}

\subsection{Component Context (Context)}

The foundation or basis for the implementation of the 2018 Asian Games training preparation program based on SK PSSI No. SKEP / V / II-2018 concerning the appointment of Head Coach, Assistant Coach and Goalkeeper Coach for the 2018 Asian Football National Women's Team and AFF Womens Championship 2018, the name in SK is tasked with understanding each of their duties and functions, and synergizing with the official ranks. other team.

PSSI (Indonesian Football Association) in organizing a Training Camp has good clarity and function as the highest football management institution in Indonesia, so it is very feasible to carry out this Training Camp. In addition, PSSI has a variety of potential supporters which include: appreciation and support from the public and sponsors who are enthusiastic in developing Indonesian women's football, have a clear organizational structure, human resources, facilities and infrastructure and partnership support from various parties.

\subsection{Component Input (Input)}

In the input component that relates to the characteristics and resources of available players, it can be concluded that the players participating in this Training Camp are some of the female soccer players in Indonesia, why can researchers assume that, because HR players are only from Cup and Tournament championships In Bali and the monitoring players directly from the trainers themselves, the nature of this is not good for the 
development of Indonesian women's football. A good player will be born from a neatly structured competition.

\subsection{Process Components (Process)}

The results of the evaluation of the suitability of the training program with the schedule of training camps available for approximately 6 months, have met the criteria. In the component of player compliance with discipline in the training process that applies, showing high intensity in each training session given. This is supported by the availability of dormitories at NYTC Sawangan for all selected players so that the entire training schedule can be well followed by 2018 Asian Games players.

\subsection{Component Results (Product)}

The product evaluation results are: (a) the results of evaluations of individual 2018 Asian Games players, (b) the results of evaluations of the team's achievements at the 2018 Asian Games. If based on the results of total value recapitulation with existing criteria, then the results obtained both for Indonesian women's soccer players, the results of the matches at the 2018 Asian Games get 1 draw and 2 defeats.

\section{REFERENCES}

[1] Madaus, George, Michael, Scriven, dan Daniel L. Stufflebeam. "Evaluation ModelsViewpoints on Educational and Human Services Evaluation". Boston: Kluwer-Nijhoff Publishing, 1987. pp. 87

[2] Blaine, Worten, James, Sanders, Jodi, dan Fitzpatrick. "Program Evaluation Alternatives Approach and Practical Guidelines". Boston: Pearson EducationInc., 2004. pp. 62

[3] S. Arikunto. "Dasar-dasar Evaluasi Pendidikan". Jakarta: Bumi Aksara, 2008. pp. 19. 